\title{
Superhydrophobic Film on Hot-Dip Galvanized Steel with Corrosion Resistance and Self-Cleaning Properties
}

\author{
Chongchong Li $1,2,3$, Ruina Ma ${ }^{1,2,3}$, An Du 1,2,3, Yongzhe Fan ${ }^{1,2,3, *}$, Xue Zhao ${ }^{1,2,3, *}$ \\ and Xiaoming Cao ${ }^{1,2,3}$ \\ 1 School of Materials Science and Engineering, Hebei University of Technology, Tianjin 300130, China; \\ 201711801008@stu.hebut.edu.cn (C.L.); marn@hebut.edu.cn (R.M.); duan@hebut.edu.cn (A.D.); \\ caoxiaoming@hebut.edu.cn (X.C.) \\ 2 Key Lab for New Type of Functional Materials in Hebei Province, Tianjin 300130, China \\ 3 Tianjin Key Lab Material Laminating Fabrication and Interface, Tianjin 300132, China \\ * Correspondence: fyz@hebut.edu.cn (Y.F.); zhaoxue@hebut.edu.cn (X.Z.); Tel.: +86-186-3089-7161 (Y.F.)
}

Received: 8 August 2018; Accepted: 27 August 2018; Published: 31 August 2018

\begin{abstract}
Super-hydrophobic film with hierarchical micro/nano structures was prepared by galvanic replacement reaction process on the surface of galvanized steel. The effects of the etching time and copper nitrate concentration on the wetting property of the as-prepared surfaces were studied. Scanning electron microscopy/energy dispersive spectroscopy (SEM/EDS), X-ray diffraction (XRD), Fourier transform infrared spectroscopy (FTIR), X-ray photoelectron spectroscopy (XPS), and electrochemical technique were employed to characterize the surface morphology, chemical composition, and corrosion resistance. The stability and self-cleaning property of the as-fabricated super-hydrophobic film were also evaluated. The super-hydrophobic film can be obtained within $3 \mathrm{~min}$ and possesses a water contact angle of $164.3^{\circ} \pm 2^{\circ}$. Potentiodynamic polarization measurements indicated that the super-hydrophobic film greatly improved the corrosion resistance of the galvanized steel in $3.5 \mathrm{wt} \% \mathrm{NaCl}$ aqueous solution. The highest inhibition efficiency was estimated to be $96.6 \%$. The obtained super-hydrophobic film showed good stability and self-cleaning property.
\end{abstract}

Keywords: super-hydrophobic surface; hot-dip galvanized steel; anti-corrosion resistance; self-cleaning

\section{Introduction}

Galvanizing is recognized as a traditional technology to protect steel free from corrosion. The hot-dipped zinc coating on steel surface can provide both barrier protection and cathodic protection [1]. However, galvanized layers, in highly aggressive environments (such as coastal or marine environments), may suffer atmospheric corrosion. High humidity and salt spray ingress can accelerate the corrosion process, which makes it unable to provide adequate corrosion protection to ensure long-term service life for steel substrate [2]. Chromium-containing passivation has been extensively employed as an effective method to inhibit corrosion of zinc layer. However, now it has been restricted due to its adverse effects on human health and environmental. To suppress this issue, a few techniques have been developed to mitigate the corrosion process of galvanized layer, such as corrosion inhibitors [3], graphene based coatings [4], sol-gel protective coatings [5-7], silicon protective coatings [8], and so on.

Nowadays, with the advances of non-wetting bio-inspired materials the technology of corrosion resistant for metals has been broadened [9-13]. Super-hydrophobic surfaces (water contact angle larger than $150^{\circ}$ and contact angle hysteresis less than $10^{\circ}$ ), which exhibit excellent self-cleaning, water repulsion, anti-icing, and corrosion resistance characteristics, have drawn much attention both 
in scientific research and practical applications. Super-hydrophobic film keeps corrosion at coastal areas by not allowing a large volume of corrosive liquids to interact with the active surface. It has shown great potential for corrosion control [14].

To fabricate super-hydrophobic surfaces, modifying a rough surface with low energy materials and roughing low surface materials are the most commonly used methods. Techniques such as chemical etching [15], layer by layer deposition [16], sol-gel [17], electrochemical reaction and deposition [18,19], spray [20], solution-immersion method [21], and laser etching [22] have been used to create rough surfaces with multiple scales structures. Up to now, many super-hydrophobic surfaces have been created based on various substrates such as polymers [23], glasses [24], metals [25-27], fabrics [28], etc. Among these, fabrication of super-hydrophobic surfaces on metallic materials play a significant role in considerable industries due to its water-repel and self-cleaning properties.

To date, super-hydrophobic films have been made on various engineering materials such as aluminum, copper, magnesium, zinc, titanium, and stainless steel to improve their anti-corrosion properties [27,29-31]. However, most of the fabrication methods for super-hydrophobic surfaces are relatively complex, require special equipment, high cost and time-consuming, which greatly restrict its application in industries. Galvanizing is one of the most popular methods used to protect steel substrate in engineering and industry. Therefore, incorporate super-hydrophobic films into the design of steel products that can not only improve the corrosion resistance of the galvanized parts, but also decrease maintenance costs over the life of structure. Nevertheless, there are few reports focusing on the application of super-hydrophobic surfaces on hot-dip galvanized steel [32]. It is, therefore, important to develop a simple, environmental, and cost-effect way for large-scale fabrication of super-hydrophobic surfaces based on galvanized substrates. Numerous studies have confirmed that chemical etching is a facile way to create hierarchical structures on metallic substrates. However, the long time needed for the etching process ranged from $2 \mathrm{~h}$ to $24 \mathrm{~h}$ [33-35], which restrict its extensive application for large-scale preparation in real industry. Recently, a few facile methods was reported to fabricate super-hydrophobic surface on metals. Song et al. [36] reported a simple and highly effective method of fabricating super-hydrophobic surface on Al plates within several seconds by immersing the $\mathrm{Cu}$ coating Al plate in ethanol solution of fluoroalkylsilane. Cao et al. [37] developed a simple preparation method for super-hydrophobic surface on zinc within 5 min through a displacement reaction between a zinc plate and an acidic $\mathrm{SnCl}_{2}$ solution without surface modification. However, most of the researches focused on the preparation methods [38-40], and there is a lack of in-depth study of its formation mechanism and coating properties.

In our present work, we report a simple and fast method, which is inspired by Song et al., for constructing a super-hydrophobic film with hierarchical structure on galvanized steel surface. The super-hydrophobic film can be fabricated within $3 \mathrm{~min}$. In addition, the formation mechanism of the super-hydrophobic process was investigated. The corrosion resistance, stability, and self-cleaning properties of the as-fabricated super-hydrophobic film was also evaluated in this study. From a viewpoint of industry application, the presented method is more facile and cost-effective than the works reported before, which can be potentially used for the large-scale preparation of super-hydrophobic surfaces based on galvanized steel.

\section{Experiment}

\subsection{Materials}

Commercially available Q235 steel plates were purchased from Tianjin YiChi Steel sale Co., Ltd., Tianjin, China. Zinc ingot (99.995\%) were purchased from Zhuzhou Smelter Group Co., Ltd., Zhuzhou, China. Cupric hydrate, acetone, anhydrous ethanol, and stearic acid were obtained from Tianjin Fengchuan Chemical Reagent Technologies Co., Ltd., Tianjin, China. All the reagents used were analytical-grade and used as received without further purification. 


\subsection{Sample Preparation}

Q235 steel plates specimens, with a size of $3.5 \mathrm{~cm} \times 5 \mathrm{~cm} \times 0.25 \mathrm{~cm}$, were pretreated by degreasing, pickling, fluxing processes to ensure a clean steel surface. Then the steel articles were immersed in a bath of molten zinc $\left(\approx 450{ }^{\circ} \mathrm{C}\right.$; zinc $\left.\geq 99.995 \%\right)$. The as-fabricated galvanized steel samples were ultrasonically degreased with acetone and ethanol for $10 \mathrm{~min}$ respectively. Then the specimens were rinsed with deionized water three times. After that, the galvanized steel samples were immersed vertically in a $50 \mathrm{~mL}$ cupric hydrate solution (with $\mathrm{Cu}^{2+}$ concentration ranging from $0.05 \mathrm{M}$ to $0.2 \mathrm{M}$ ) for different time at ambient temperature. Hereafter, the immersed substrates were rinsed with deionized water to remove the residual salts and dried under a stream of hot air. Finally, the samples were immersed in a $0.05 \mathrm{M}$ stearic acid (STA, with low surface energy of about $30.03 \mathrm{~mJ} / \mathrm{m}^{2}$ [41]) ethanol solution for different time, rinsed with anhydrous ethanol, and then dried under a heat airflow at a temperature about $80^{\circ} \mathrm{C}$ for $10-20 \mathrm{~s}$. The schematic fabrication process is shown in Figure 1. For ease of understanding, Table 1 shows the details of each sample prepared.
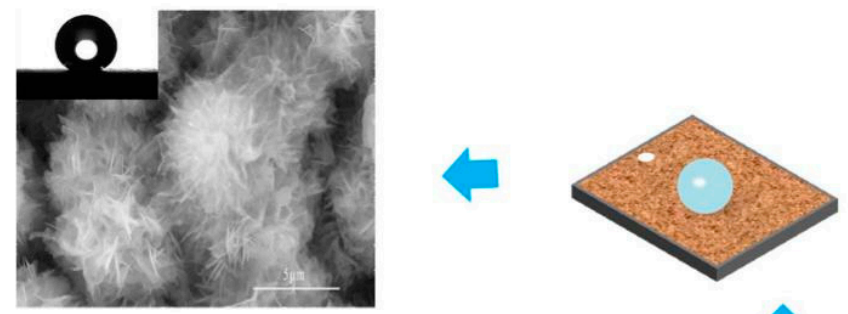

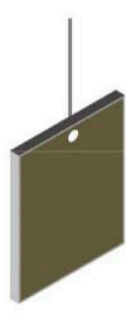

Q235 steel plate

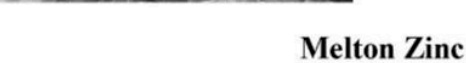

$\left(450^{\circ} \mathrm{C}\right)$

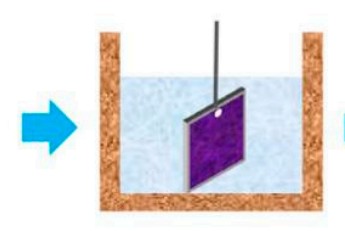

Pretreatment Hot Dipped Galvanizing Etching process
processes

Figure 1. Schematic fabrication process of super-hydrophobic galvanized steel sheet.

Table 1. Details of the samples prepared.

\begin{tabular}{cc}
\hline Sample & Details \\
\hline Blank sample & Samples without any treatment \\
Stearic acid (STA) modified sample & Samples only modified with stearic acid (STA) \\
Etched sample & Samples after immersion in $\mathrm{Cu}\left(\mathrm{NO}_{3}\right)_{2}$ aqueous solution without STA modification \\
Super-hydrophobic sample (SHS) & Samples etched by $\mathrm{Cu}\left(\mathrm{NO}_{3}\right)_{2}$ at optimum conditions and followed by STA modification \\
\hline
\end{tabular}

\subsection{Characterization of Super-Hydrophobic Film}

Static water contact angles (WCA) were measured by DAS30 contact angle measurement system (KRUSS, Hamburg, Germany) at room temperature. The volume of deionized water used for the WCA measurement was $10 \mu \mathrm{L}$. The average WCA values were obtained by measuring five different positions of the same sample. Surface morphology of the steel surface was observed by scanning electron microscope (SEM/EDS, Quanta 450 FEG, Hillsboro, OR, USA) operating at 20 kV. X-ray diffraction (XRD) was carried out to determine the phase structure of the super-hydrophobic film on galvanized steel. Chemical composition of the super-hydrophobic film was detected by X-ray photoelectron spectrometer (XPS), using the $\mathrm{Al} \mathrm{K} \alpha$ as the excitation source. All binding energies in the spectra were corrected using standard binding energy of $\mathrm{C} 1$ s peak $(284.6 \mathrm{eV})$ as reference. The functional groups 
of super-hydrophobic film was identified by Fourier transform IR (FTIR) spectroscopy (V80, Bruker, Karlsruhe, Germany).

\subsection{Electrochemical Test}

Electrochemical tests were performed on the CHI660E electrochemical workstation using an three-electrode electrochemical system (Shanghai Chenhua Instrument, Shanghai, China), where $3.5 \mathrm{wt} \% \mathrm{NaCl}$ aqueous solution was used as electrolyte at room temperature. The samples with different treatments were used as the working electrode with an area of $1 \mathrm{~cm}^{2}$, a platinum plate, and a saturated calomel electrode (SCE) were used as the counter and reference electrode, respectively. Before measurement, the working electrode was immersed in the electrolyte until the open circuit potential $\left(E_{o c}\right)$ reached a steady state (fluctuation less than $10 \mathrm{mV}$ ). The potentiodynamic polarization curves were carried out at a scanning rate of $1 \mathrm{mV} / \mathrm{s}$ raging from $-0.2 \mathrm{~V}$ (vs. $E_{o c}$ ) to $+0.2 \mathrm{~V}$ (vs. $E_{o c}$ ). The corrosion potential ( $\left.E_{\text {corr }}\right)$ and corrosion current density $\left(i_{\text {corr }}\right)$ were determined by the resultant polarization curve. Each test was repeated at least three times to verify the repeatability of the results.

\subsection{Self-Cleaning Test}

The self-cleaning test was carried out in a glass petri dish, where the samples were placed at an inclination about $10^{\circ}$. Graphite powder $(\sim 40 \mu \mathrm{m})$, which acted as contaminant, were spread over the sample surface. Self-cleaning behavior via rolling droplets of water were recorded by a high definition video camera.

\section{Results and Discussion}

\subsection{Surface Wettability}

Surface wettability of the samples were characterized by the static water contact angle system. Figure 2 shows the static WCA on different surfaces, which presents the changes of wettability during the super-hydrophobic process. As shown in Figure 2, WCA of the blank sample (initial galvanized steel sheet) is $72 \pm 2^{\circ}$, indicating that its surface is hydrophilic. WCA of the sample modified by STA only increases to $119 \pm 2^{\circ}$. This is because the STA molecules on the surface of the galvanized steel lowered its surface free energy, making the sample hydrophobic. After immersion into $0.1 \mathrm{M}$ $\mathrm{Cu}\left(\mathrm{NO}_{3}\right)_{2}$ aqueous solution, the WCA of the etched sample decreases drastically to $9 \pm 2^{\circ}$, and its surface is completely wetted by water droplet. This may attribute to the $\mathrm{Cu}$ film coated on the surface of galvanized steel that enhance its roughness leading to the completely wetting behavior. However, after it was modified by STA, the $\mathrm{Cu}$ coated sample successfully transforms from super-hydrophilicity to super-hydrophobicity with a contact angle of $164.3 \pm 2^{\circ}$, on which the water droplets can roll off easily from the super-hydrophobic surface (SHS) without any adhesion. By this etching process, as well as low surface energy passivation process, the super-hydrophobic film can be prepared successfully on the surface of galvanized steel. 


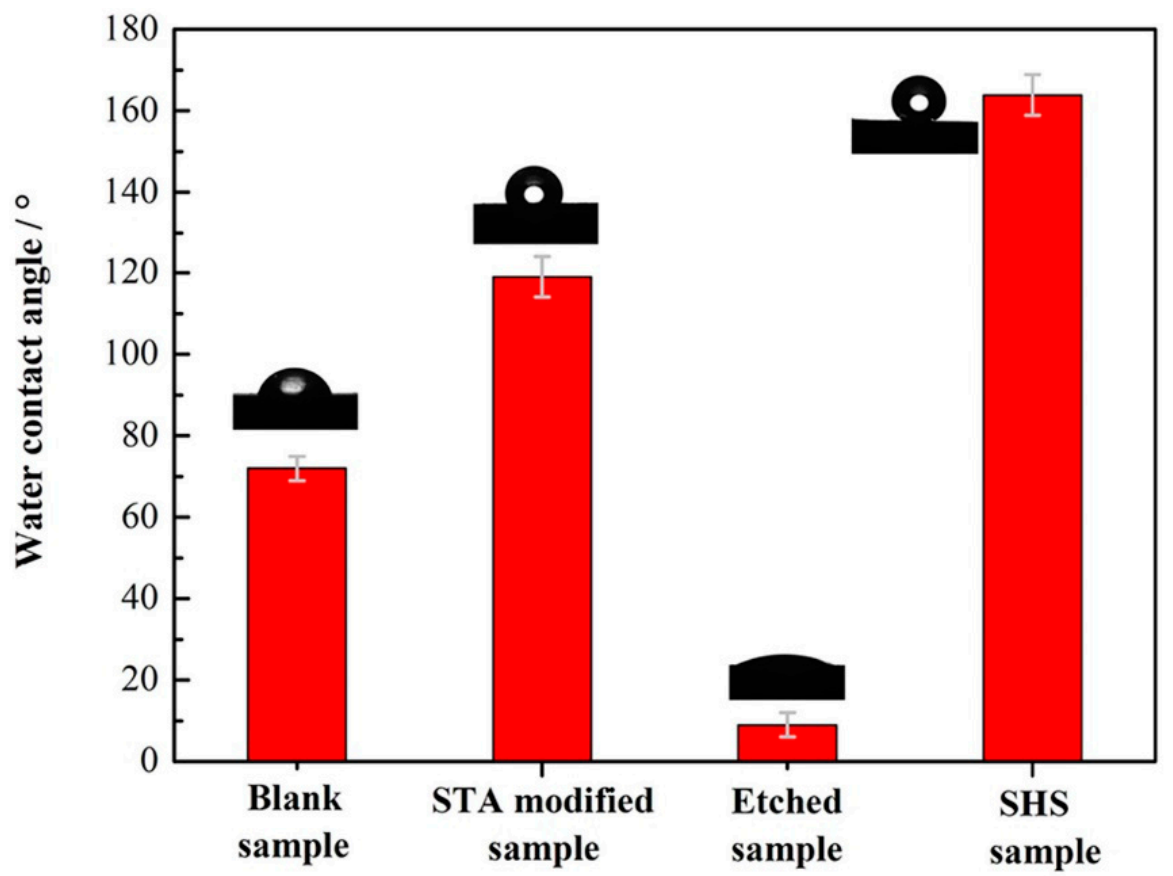

Figure 2. Static water contact angles (WCA) of the samples with different treatment process.

The immersion process mentioned above was further optimized by varying immersion time and $\mathrm{Cu}\left(\mathrm{NO}_{3}\right)_{2}$ concentration. The effect of immersion time on WCA at different copper nitrite concentrations were shown in Figure 3. All the samples were modified with STA prior to measuring the static contact angle. The WCA of STA-modified sample is $119 \pm 2^{\circ}$, and this point is given as a reference point at time zero. The dotted line in Figure 3 corresponds to a contact angle of $150^{\circ}$. When the contact angle was larger than $150^{\circ}$, the surface was consider as superhydrophobic. When the $\mathrm{Cu}\left(\mathrm{NO}_{3}\right)_{2}$ concentration is $0.05 \mathrm{M}$, the WCA of the samples increases fast after etching for $5 \mathrm{~s}$ and fluctuate at about $140^{\circ}$ as immersion time increases. However, the WCA cannot meet the requirements of super-hydrophobicity. The increase of $\mathrm{Cu}\left(\mathrm{NO}_{3}\right)_{2}$ concentration enhanced the hydrophobicity of the coatings. As Figure 3 shows that when the $\mathrm{Cu}\left(\mathrm{NO}_{3}\right)_{2}$ concentration is $0.1 \mathrm{M}$, WCA of the samples reach a super-hydrophobic level after etching for $5 \mathrm{~s}$ and slightly fluctuate as etching time increases. When the concentration of copper nitrite is $0.15 \mathrm{M}$ and $0.2 \mathrm{M}$, a similar trend can be found as the etching time increases. It can be seen from Figure 3 that the WCA reaches a maximum value of $164.3 \pm 2^{\circ}$ when the copper nitrate concentration is $0.1 \mathrm{M}$ and the optimal immersion time is $15 \mathrm{~s}$. Therefore, superhydrophobic samples fabricated under this processing conditions were used for further studies. 


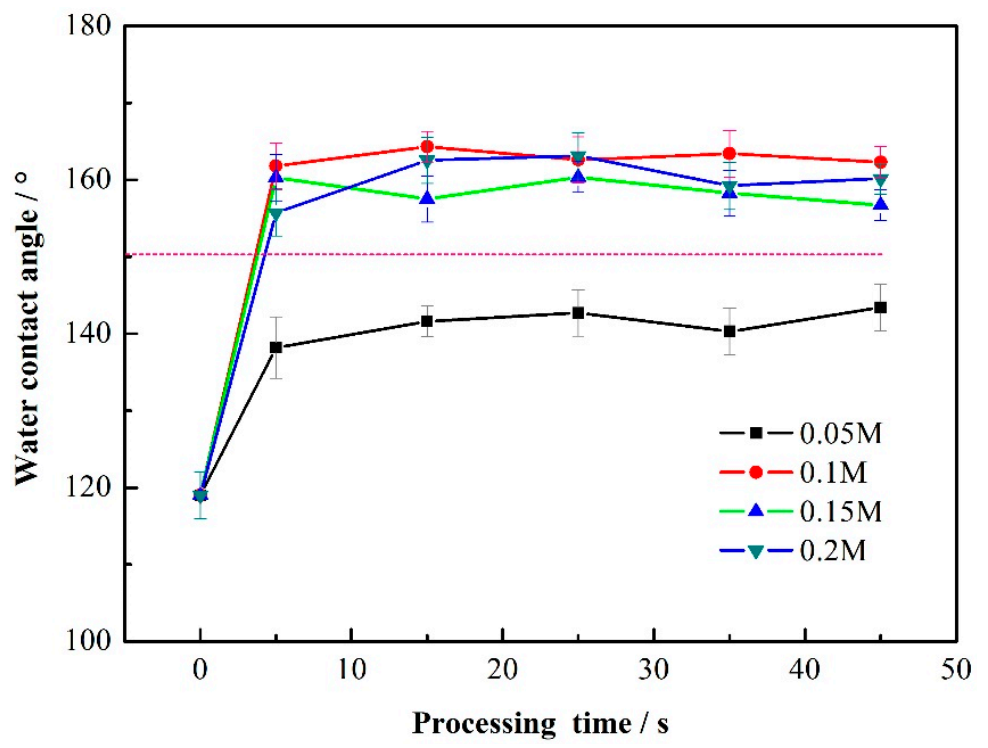

Figure 3. Effect of immersion time and copper nitrite concentration on WCA.

\subsection{Surface Morphology}

The surface morphology of different treated samples were characterized by SEM. Figure 4 shows the SEM images of (a) blank sample; (b) etched sample; (c) super-hydrophobic sample, respectively; and $(\mathrm{d}-\mathrm{f})$ are the corresponding high magnification images. It can be found from Figure $4 a, d$ that the initial galvanized steel surface is relatively flat, except for some scratches. Figure $4 \mathrm{~b}$ shows the surface morphology of the sample after etching with $0.1 \mathrm{M}$ copper nitrate solution for $15 \mathrm{~s}$. There are a large amount of tiny spherical particles, with an average diameter of $3 \mu \mathrm{m}$, on the surface of the galvanized sheet. It can be further seen from Figure $4 \mathrm{e}$ that the tiny spherical particles are composed of hierarchical micro/nano structures. This hierarchical structure improves the surface roughness, which is helpful to enhance the super-hydrophilic property. Figure 4c,f show the surface morphology of the etched sample modified by stearic acid. From the images we can see that the hierarchical micro/nano structures become more distinct, and the pompom-like structures are filmed on the surface of galvanized. It is these pompom-like hierarchical micro/nano structures that endow super-hydrophobic and rolling off properties to galvanized plate surfaces. 

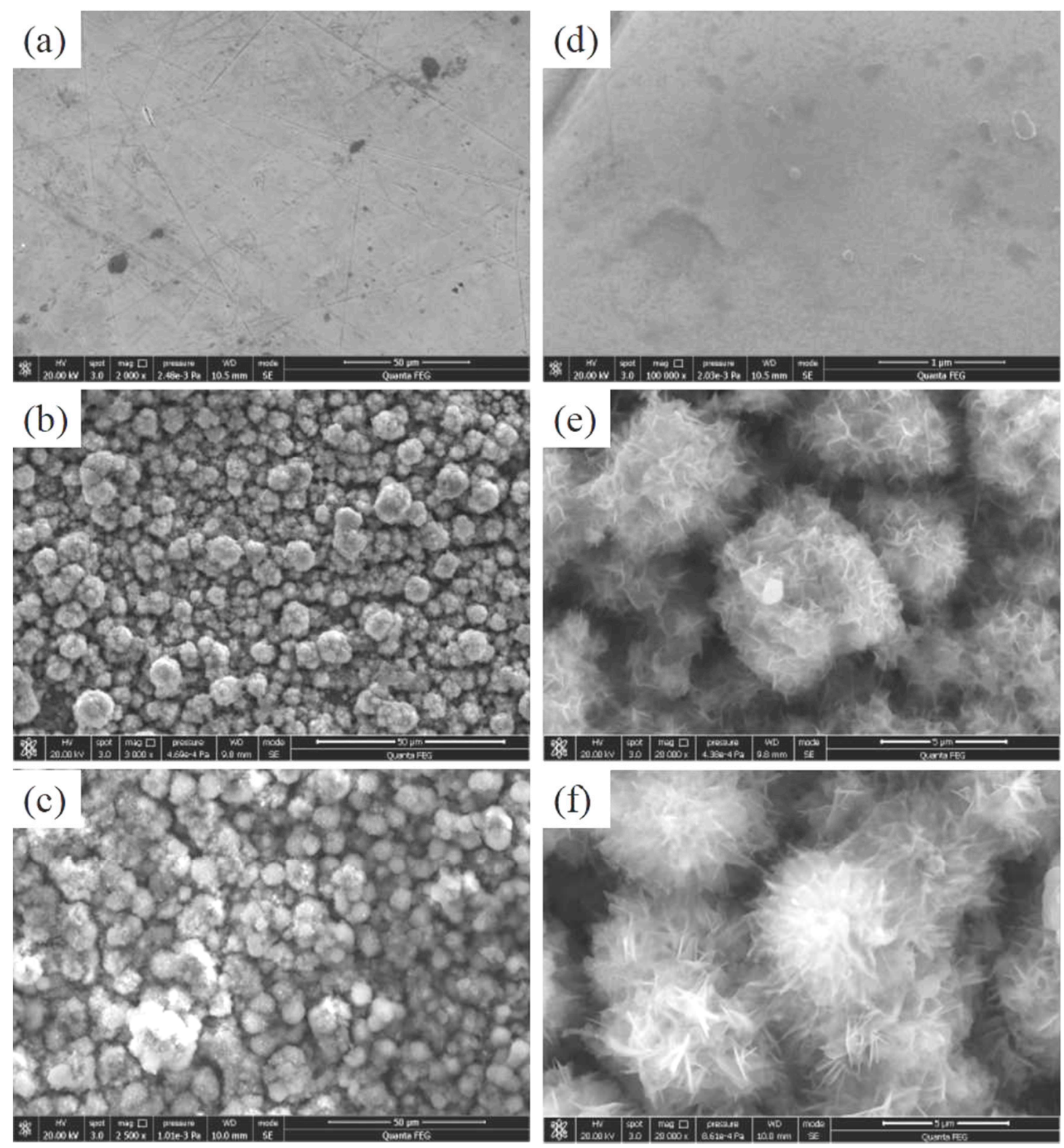

Figure 4. SEM images of (a) blank sample; (b) etched sample; (c) super-hydrophobic sample, respectively; and (d-f) are the corresponding high magnification images, respectively.

\subsection{Surface Composition Analysis}

\subsubsection{EDS Analysis}

Figure 5 shows the surface elemental composition of (a) blank sample; (b) etched sample; (c) super-hydrophobic sample, respectively. The illustrations are physical topographies of the sample surfaces. The EDS analysis results confirm that the surface of initial galvanized sheet (Figure 5a) is mainly composed of $\mathrm{Zn}(99.84 \%)$ element. As can be seen from Figure $5 \mathrm{~b}$, the etched sample surface consists of $\mathrm{Zn}, \mathrm{Cu}, \mathrm{O}, \mathrm{N}$, and Fe. The micro/nano structures on the etched sample surface can be attributed to the galvanic replacement deposition between $\mathrm{Zn}$ and $\mathrm{Cu}\left(\mathrm{NO}_{3}\right)_{2}$, which can be explained by the following reaction:

$$
\mathrm{Zn}+\mathrm{Cu}^{2+} \longrightarrow \mathrm{Cu}+\mathrm{Zn}^{2+}
$$

The appearance of $\mathrm{N}$ and parts of $\mathrm{O}$ may ascribe to the residual from the solution. Since the basic substrate is steel, the element Fe can be ascribe to the steel substrate. The increase of oxygen 
content suggests that more oxygen is brought into the etched sample surface, and might generate metal oxides [42]. Furthermore, a large amount of Zn element is detected on the deposited particles, which demonstrate that the $\mathrm{Zn}^{2+}$ not completely enter into the solution but remains at the reaction interface. The super-hydrophobic sample surface consists of $\mathrm{C}, \mathrm{O}, \mathrm{Zn}, \mathrm{Cu}$, and Fe, as shown in Figure 5c. The new peak due to $C(51.73 \%)$ appeared in Figure $5 c$, while the $N$ element disappeared and the content of $\mathrm{Zn}, \mathrm{Cu}$, and $\mathrm{O}$ decreased significantly. These variations indicate that the STA is grafted on the surface of the etched sample, which has a significant impact to its wettability.
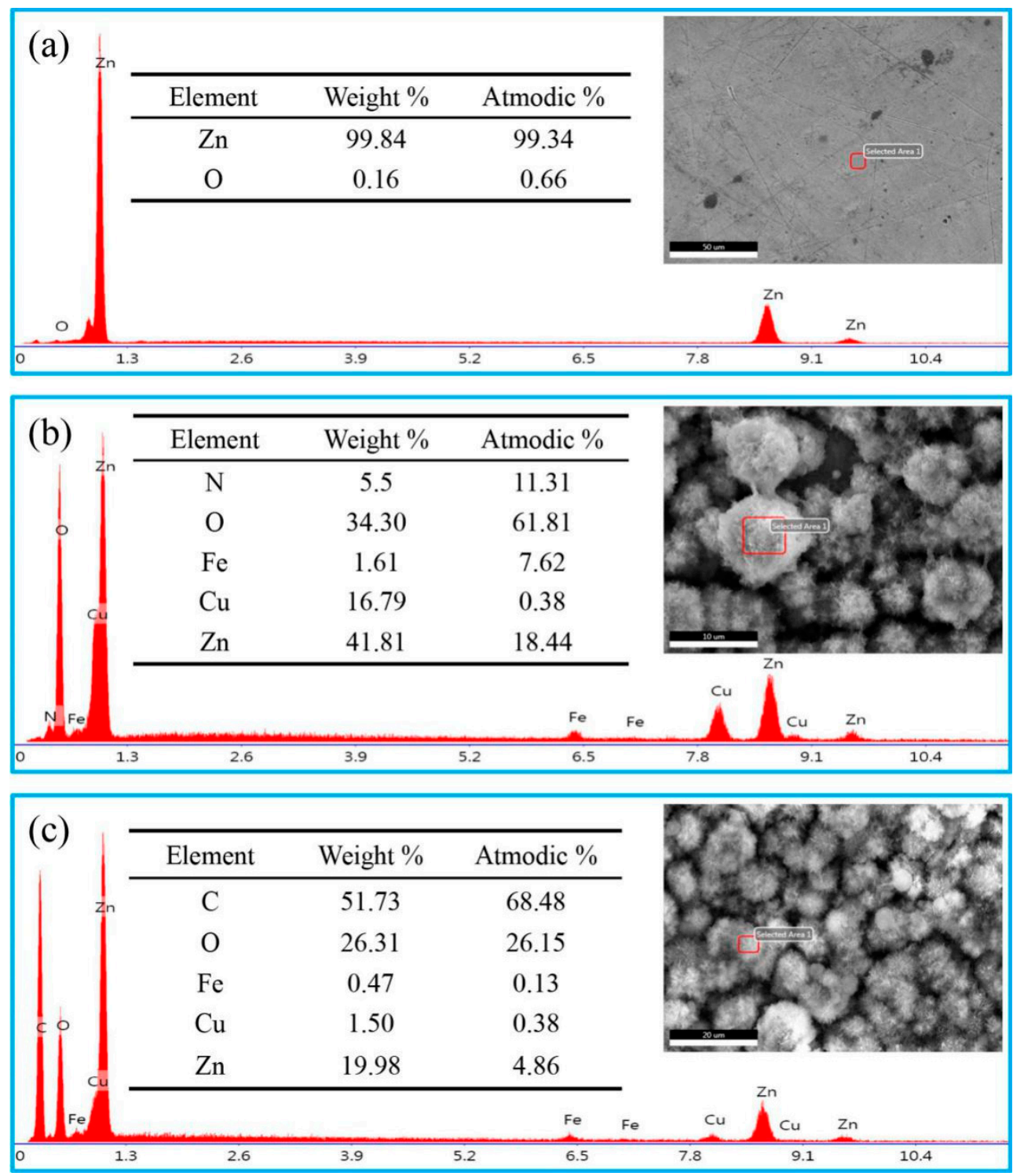

Figure 5. EDS spectra of (a) blank sample; (b) etched sample; (c) super-hydrophobic sample.

\subsubsection{XRD Analysis}

The X-ray diffraction (XRD) was carried out to further determine the phase structure of the super-hydrophobic film on galvanized steel. Figure 6 illustrates the X-ray diffraction and results of the prepared samples. The low angle X-ray diffraction (Figure 6a) results demonstrates that two distinct peaks at $6.57^{\circ}, 9.15^{\circ}$ was observed on the superhydrophobic sample surface, which corresponds to Zinc stearate $\left(\mathrm{Zn}\left[\mathrm{CH}_{3}\left(\mathrm{CH}_{2}\right)_{16} \mathrm{COO}\right]_{2}\right.$, abbreviated as $\left.\mathrm{Zn}(\mathrm{SA})_{2}\right)$. It should be noted that no characteristic peaks has been found on the blank sample and etched sample surfaces. Meanwhile, some weak peaks that corresponds to $\mathrm{ZnO}$ were detected on the etched sample, demonstrating the oxidation of Zinc. 
Besides, some characteristic peaks at $36.3^{\circ}, 39.2^{\circ}, 43.5^{\circ}, 70.8^{\circ}$ in Figure $6 \mathrm{~b}, \mathrm{c}$ and $77.1^{\circ}$ in Figure $6 \mathrm{~d}$, respectively, which are in good agreement with the characteristic peaks of Zn(002), (100), (101), (103), and (004). This arises from the galvanized zinc layer.
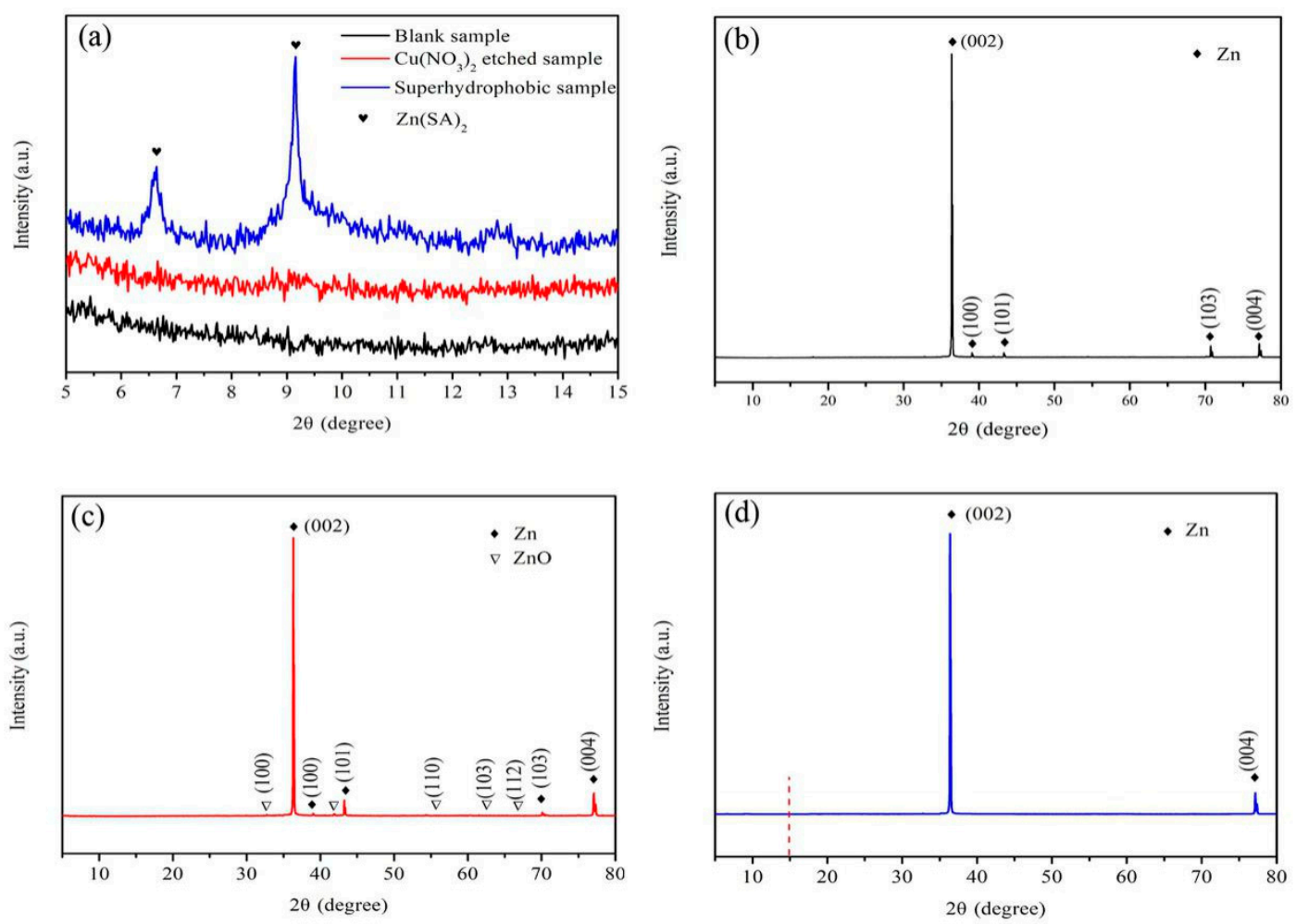

Figure 6. X-ray diffraction results of the prepared samples: (a) the low angle X-ray diffraction; (b) blank sample; (c) etched sample; (d) super-hydrophobic sample.

\subsubsection{FTIR Analysis}

FTIR spectra was employed to study the functional group of the as-prepared superhydrophobic film. Figure 7 shows the FTIR spectra results of stearic acid and the compound scratched from the superhydrophobic film, respectively. It can be seen that the characteristic peaks related to alkyl chain, such as asymmetric vibrations of $-\mathrm{CH}_{3}\left(2953 \mathrm{~cm}^{-1}\right)$, asymmetric and symmetric vibrations of $-\mathrm{CH}_{2}\left(2846 \mathrm{~cm}^{-1}, 2918 \mathrm{~cm}^{-1}\right)$ can be found in the high frequency region of both stearic acid and superhydrophobic film [26]. It is well known that the carboxyl group (COO-) from stearic acid appears at $1702 \mathrm{~cm}^{-1}$. However, it was nearly disappeared in the superhydrophobic sample surface. Compared with the FTIR spectrum of stearic acid, the superhydrophobic film exhibit some newly formed adsorption peaks at $1539 \mathrm{~cm}^{-1}, 1461 \mathrm{~cm}^{-1}$, and $1398 \mathrm{~cm}^{-1}$, which correspond to asymmetric and symmetric stretches of COO-group [43]. Thus based on the FTIR analysis, we can deduce that the stearic acid is not physically absorbed on the film, but instead reacts chemically with the particles on the surface of galvanized steel, and $\mathrm{Zn}$ stearate $\left(\mathrm{Zn}\left[\mathrm{CH}_{3}\left(\mathrm{CH}_{2}\right)_{16} \mathrm{COO}\right]_{2}\right)$ with low surface energy is most likely formed on the superhydrophobic surface. 


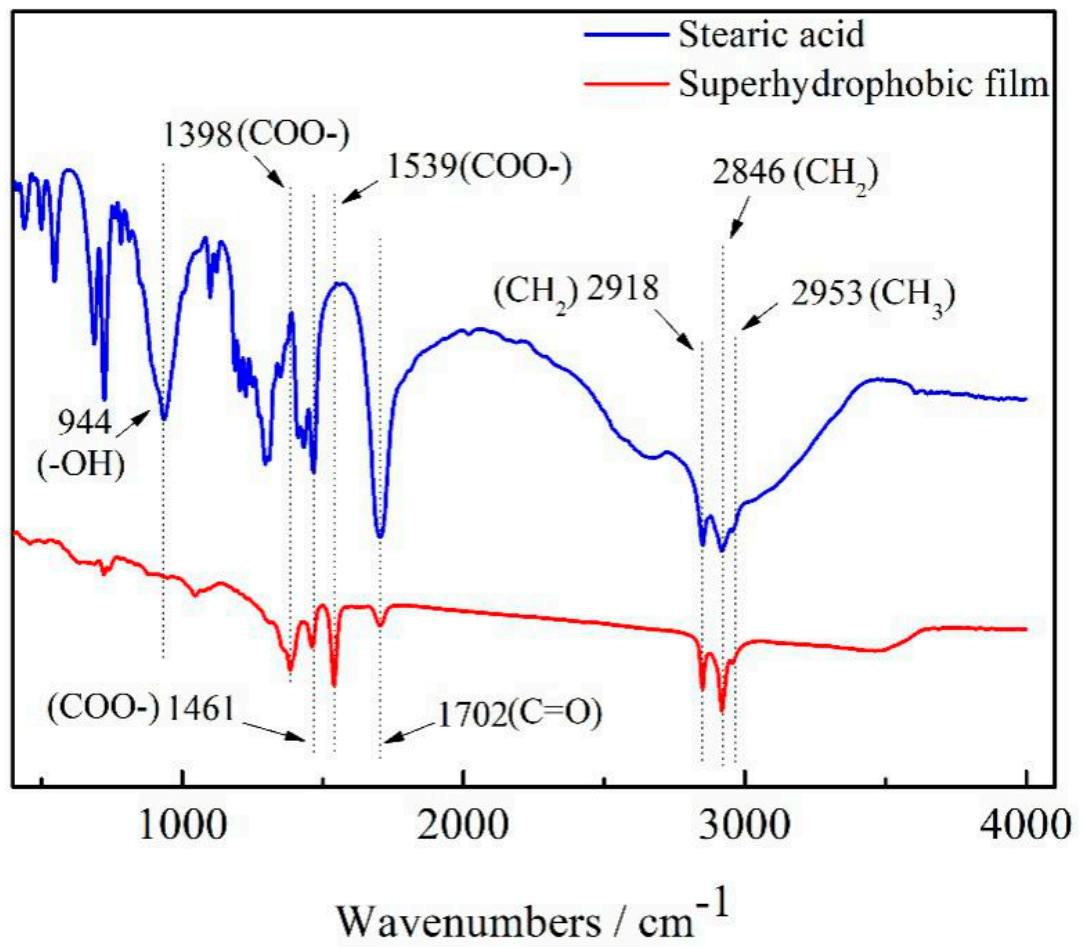

Figure 7. FTIR spectra of stearic acid and superhydrophobic film.

\subsubsection{XPS Analysis}

The formation mechanism was further confirmed with XPS measurements, as shown in Figure 8. The curves labeled with (A) and (B) in Figure 8 a are $\mathrm{Cu}$ coated sample and super-hydrophobic sample, respectively. The survey region shown in Figure 8 a indicates that $\mathrm{Zn}, \mathrm{O}, \mathrm{C}$, and $\mathrm{Cu}$ are main components on the sample surface. Figure $8 \mathrm{~b}$ shows the high resolution core level spectra of the copper element. The peaks at binding energies of $963.2 \mathrm{eV}\left(\mathrm{Cu} 2 \mathrm{p}_{1 / 2}\right)$ and $952.3\left(\mathrm{Cu} 2 \mathrm{p}_{1 / 2}\right)$ are attributed to the $\mathrm{Cu} 2 \mathrm{p}$ region of metallic copper [21], indicating that copper was deposited on the galvanized steel surface. The other two peaks located at $934.8 \mathrm{eV}\left(\mathrm{Cu} 2 \mathrm{p}_{3 / 2}\right)$ and $932.7\left(\mathrm{Cu} 2 \mathrm{p}_{3 / 2}\right)$, which can be implied to the oxidation of the deposited copper particles after drying process, should be assigned to the copper element in $\mathrm{Cu}-\mathrm{O}$. However, nearly all the $\mathrm{Cu} 2 \mathrm{p}$ spectra peaks disappeared after modified by STA, indicating that a layer of stearic acid film was absorbed on the surface of the micro-copper particles on the surface of the galvanized steel plate. Since no other carbon-containing substances was introduced during the etching process. Therefore, the weak carbon peak in Figure 8c-A is most likely due to the intervention of air. As can be seen from Figure 8c-B, a strong peak of carbon element at binding energy of $285.0 \mathrm{eV}$ was detected. The high-resolution core level of C1s after STA modification is resolved into two components: $288.8 \mathrm{eV}$ and $284.75 \mathrm{eV}$. The peak located at $288.8 \mathrm{eV}$ can be attributed to the carbon element in the carbonyl bonds (-COO-), while the peak at 284.75 is attributed to the C-C and C-H functional group [27]. This is in good accordance with the results of FTIR. Figure 8d depicts the $\mathrm{Zn} 2 \mathrm{p}$ high resolution of the sample before (black) and after STA modification (red). It is found that the spectra intensity of the sample without STA modification are stronger than the SHS one. The binding energy of $\mathrm{Zn} 2 \mathrm{p}_{3 / 2}$ and $\mathrm{Zn} 2 \mathrm{p}_{1 / 2}$ peaks are centered at around $1022.1 \mathrm{eV}$ and $1045.2 \mathrm{eV}$, respectively with a spin-energy separation of about $23 \mathrm{eV}$. This results suggests that the zinc element exists in its ionic form $\left(\mathrm{Zn}^{2+}\right)$ consistent with Wertheim's results [44] and the XRD results where $\mathrm{ZnO}$ phases and $\mathrm{Zn}(\mathrm{SA})_{2}$ were detected before and after STA modification, respectively. 

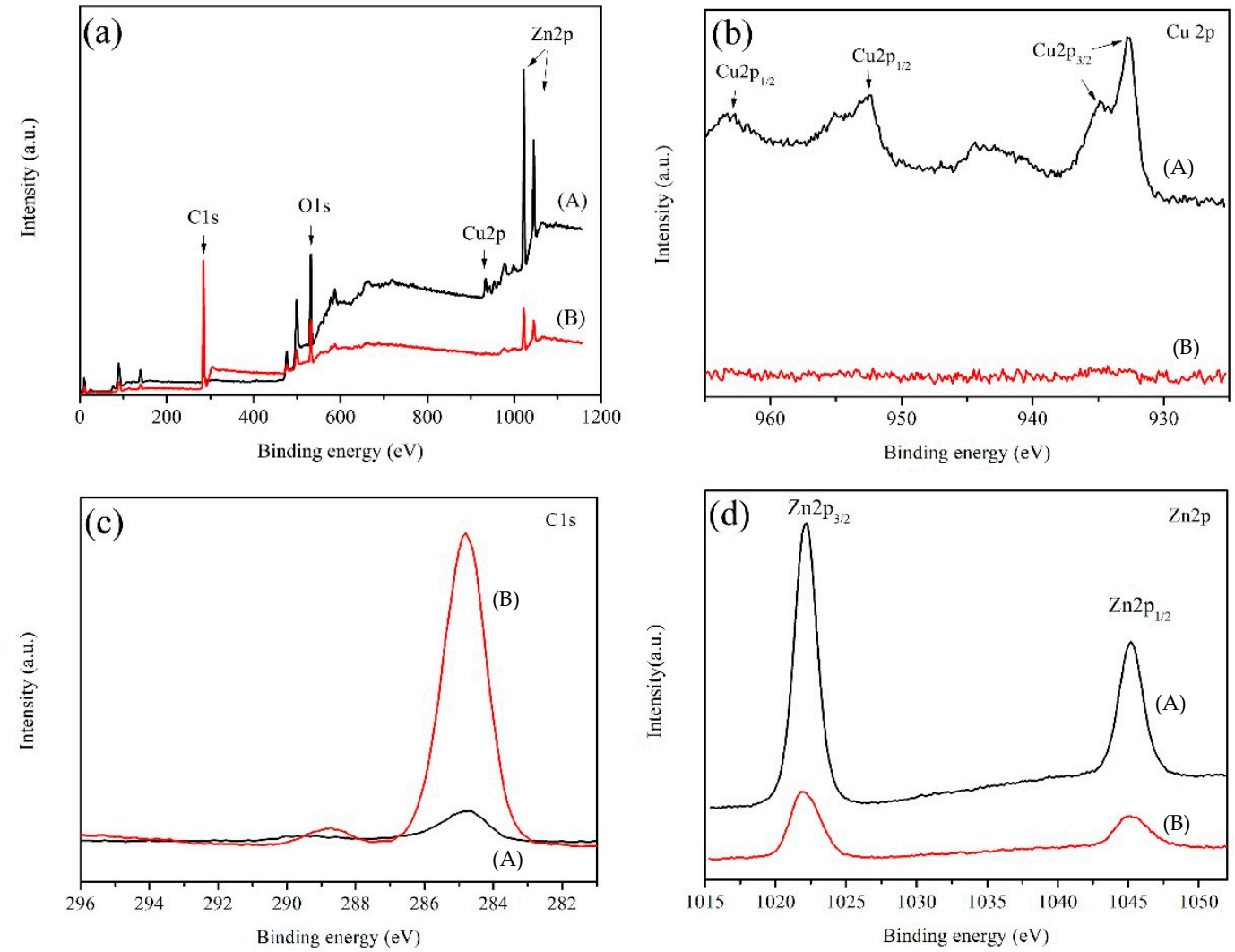

Figure 8. XPS spectra of (A) Cu coated sample and (B) super-hydrophobic sample: (a) survey region; (b) Cu2p; (c) C1s; (d) Zn2p.

\subsection{Theoretical Formation Mechanism for Super-Hydrophobic Surface}

The formation mechanism of the super-hydrophobic process has been studied in this paper. Based on the comprehensive analysis results (SEM/EDS, FT-IR, XRD, XPS), we proposed a possible schematic model to illustrate the formation mechanism of the super-hydrophobic surfaces, as shown in Figure 9. When the Galvanized steel substrate was immersed in the copper nitrate solution, a galvanic replacement reaction between $\mathrm{Zn}$ and $\mathrm{Cu}\left(\mathrm{NO}_{3}\right)_{2}$ occurred (Equation (1)). Zinc ions $\left(\mathrm{Zn}^{2+}\right)$ were forced to release from the galvanized zinc layer, meanwhile the copper ions $\left(\mathrm{Cu}^{2+}\right)$ get electrons to form copper and deposited on the substrate. Interestingly, both EDS and XPS results indicate that a large amount of $\mathrm{Zn}$ element is detected on the deposited particles. Therefore, we infer that the $\mathrm{Zn}^{2+}$ not completely enter into the solution but remains at the reaction interface between $\mathrm{Zn}$ layer and aqueous solution (as shown in Figure 9a). After the galvanic reaction process, the obtained surfaces exhibit super-hydrophilic property, where the water can completely spread (as shown in Figure 9a). When the above-obtained surfaces were modified with STA, the STA molecules combined with the composite particles $\left(\mathrm{Cu} / \mathrm{Zn}^{2+}\right)$, generating zinc stearate $\left(\mathrm{Zn}\left[\mathrm{CH}_{3}\left(\mathrm{CH}_{2}\right)_{16} \mathrm{COO}\right]_{2}\right)$ and copper stearate $\left(\mathrm{Cu}\left[\mathrm{CH}_{3}\right.\right.$ $\left.\left(\mathrm{CH}_{2}\right)_{16} \mathrm{COO}_{2}\right)$. In addition, some STA molecules can be attached to the surface of composite particles by physical adsorption (as shown in Figure 9b). Thus the super-hydrophobic surface with micro/nano structures was formed. The detailed reaction equations are described as follows [43]:

$$
\begin{gathered}
\mathrm{Zn}+\mathrm{Cu}^{2+} \longrightarrow \mathrm{Cu}+\mathrm{Zn}^{2+} \\
\mathrm{Zn} \longrightarrow \mathrm{Zn}^{2+}+2 \mathrm{e}^{-} \\
2 \mathrm{Zn}+\mathrm{O}_{2} \longrightarrow 2 \mathrm{ZnO} \\
2 \mathrm{Cu}+\mathrm{O}_{2} \longrightarrow 2 \mathrm{CuO}
\end{gathered}
$$




$$
\begin{aligned}
& \mathrm{Zn}^{2+}+\mathrm{CH}_{3}\left(\mathrm{CH}_{2}\right)_{16} \mathrm{COOH} \longrightarrow \mathrm{Zn}\left[\mathrm{CH}_{3}\left(\mathrm{CH}_{2}\right)_{16} \mathrm{COO}_{2}+2 \mathrm{H}^{+}\right. \\
& \mathrm{Cu}^{2+}+\mathrm{CH}_{3}\left(\mathrm{CH}_{2}\right)_{16} \mathrm{COOH} \longrightarrow \mathrm{Cu}\left[\mathrm{CH}_{3}\left(\mathrm{CH}_{2}\right)_{16} \mathrm{COO}_{2}+2 \mathrm{H}^{+}\right.
\end{aligned}
$$

It is well known that hierarchical micro/nano structures play an important role in the wettability of a solid surface. A large amount of air can be trapped in the interspace of the hierarchical structures, which can lead to the larger CA and smaller SA according to the Cassie-Baxter equation $[45,46]$ :

$$
\cos \theta=f \cdot \cos \theta_{0}+f-1
$$

where $f$ is the area fraction of liquid-solid interface and $\theta$ and $\theta_{0}$ represent the WCA of the composite hierarchical structures surface and the smooth surfaces, respectively. Herein, it was calculated from the obtained data that $f=0.03$, demonstrating that the contact-area fraction of the water-air interface is 0.97 . The results demonstrate that the air occupies about $97 \%$ of the contact area between super-hydrophobic galvanized substrate and water droplet. It reveals that the hierarchical micro/nano structures with low surface energy keep corrosion at corrosive areas by not allowing a large volume of corrosive liquids to interact with the active surface, which have showed great potential for corrosion control.

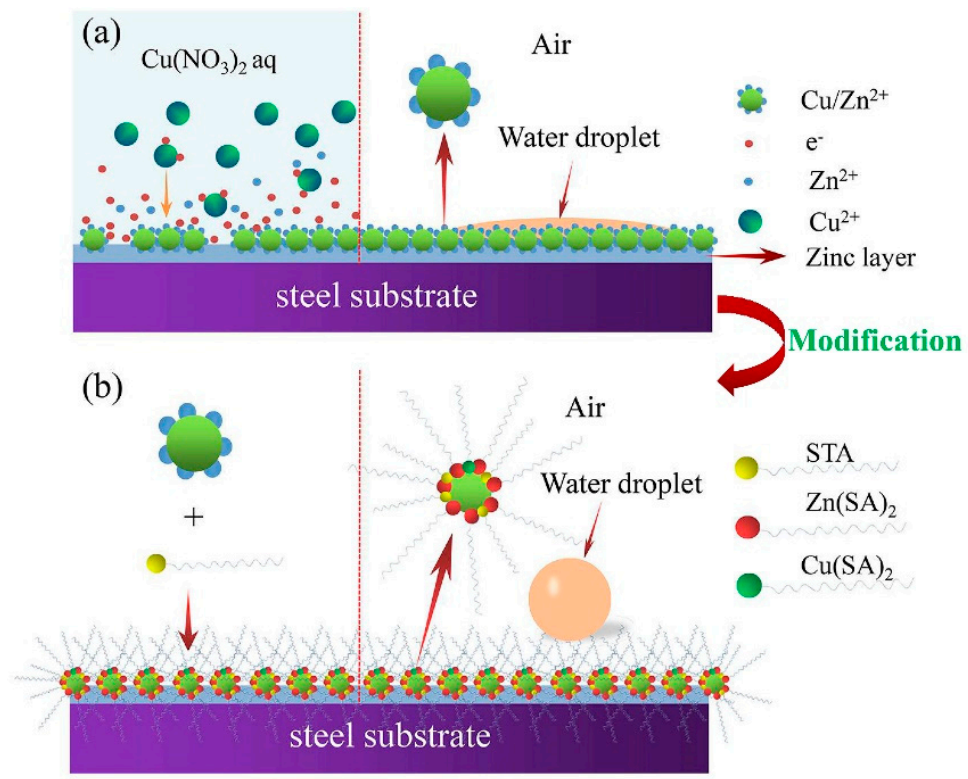

Figure 9. Schematic illustration of the formation mechanism for super-hydrophobic film: (a) etching process and wettability; (b) STA modification process and wettability.

\subsection{Corrosion Resistance of Super-Hydrophobic Film}

A comparative study on the corrosion resistance of the galvanized steel plates with different wetting properties was conducted using electrochemical method. Figure 10 shows the potentiodynamic polarization curves of the galvanized steel plates with different wetting properties in $3.5 \mathrm{wt} \% \mathrm{NaCl}$ solution. The corrosion potential $E_{c o r r}$ and the corrosion current density $i_{c o r r}$ from the Tafel polarization curves are tabulated in Table 2 for the ease of comparison. As can be clearly seen from Figure 10 and Table 2, the super-hydrophobic sample positively increases from $-1.096 \mathrm{~V}$ to $-0.844 \mathrm{~V}$, which exhibits significantly higher potential compared to that of blank sample. Accordingly, the super-hydrophobic sample shows an appreciable reduction in corrosion current density $\left(1.632 \times 10^{-6} \mathrm{~A} / \mathrm{cm}^{2}\right)$ in comparison to the corrosion current density of the blank sample $\left(4.802 \times 10^{-5} \mathrm{~A} / \mathrm{cm}^{2}\right)$. 


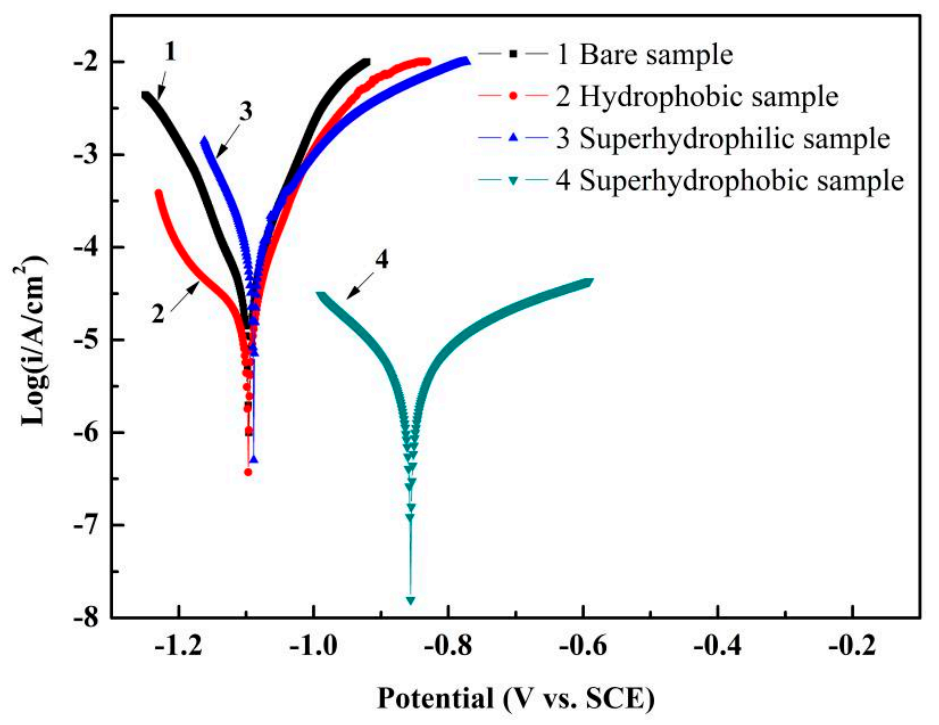

Figure 10. Potentiodynamic polarization curves of the galvanized steel plates with different wetting properties in $3.5 \mathrm{wt} \% \mathrm{NaCl}$ solution.

Table 2. Corrosion potential $\left(E_{\text {corr }}\right)$ and corrosion current density $\left(i_{\text {corr }}\right)$ of galvanized steel samples with different wetting properties in $3.5 \mathrm{wt} \% \mathrm{NaCl}$ solution.

\begin{tabular}{cccc}
\hline Sample & $\boldsymbol{E}_{\text {corr }}(\mathrm{V})$ & $\boldsymbol{i}_{\text {corr }}\left(\mathbf{A} / \mathbf{c m}^{2}\right)$ & $\boldsymbol{\eta} \mathbf{( \% )}$ \\
\hline Blank sample & $-1.096 \pm 0.01$ & $4.802 \times 10^{-5}$ & - \\
Hydrophobic & $-1.095 \pm 0.02$ & $1.615 \times 10^{-5}$ & 66.4 \\
Super-hydrophilic & $-1.089 \pm 0.02$ & $7.652 \times 10^{-5}$ & - \\
Super-hydrophobic & $-0.844 \pm 0.03$ & $1.632 \times 10^{-6}$ & 96.6 \\
\hline
\end{tabular}

Futhermore, the corrosion current density of the super-hydrophilic sample shown in Table 2 has nearly doubled, which may be attributed to the rough surface structure on the sample. This causes an enhanced adsorption of corrosive electrolytes, making it more susceptible to corrosion. As is known to us that a higher corrosion potential or a lower corrosion current density corresponds to a lower corrosion rate and a better corrosion resistance. Therefore, the increasing of $E_{c o r r}$ and the decreasing of $i_{\text {corr }}$ indicate that the super-hydrophobic sample possesses a better corrosion resistance. This may be attributed to the formation of air layer on the super-hydrophobic sample surface that acts as a corrosion barrier to inhibit the electrons and ions transfer between substrate and electrolyte. The inhibition efficiency $(\eta)$ of the samples was calculated using the following equation [47]:

$$
\eta=\frac{\left[i_{B-\text { corr }}-i_{S-\text { corr }}\right]}{i_{B-\text { corr }}} \times 100 \%
$$

where $i_{B-\text { corr }}$ and $i_{\text {s-corr }}$ are the corrosion current density of bare sample and super-hydrophobic sample, respectively. The highest inhibition efficiency was estimated to be $96.6 \%$ for the super-hydrophobic sample.

\subsection{Stability and Self-Cleaning Properties}

The chemical stability of the as-fabricated super-hydrophobic surfaces is a critical factor to determine the feasibility for practical applications. In this study, the stability of the super-hydrophobic surfaces were examined by exposure to the outdoor environment for about 6 months. Figure 11 shows the results of WCA before and after exposure for 6 months. The results indicate that the WCA angle and roll-off property has nearly no variation for long-time exposure, and show good stability in air. 

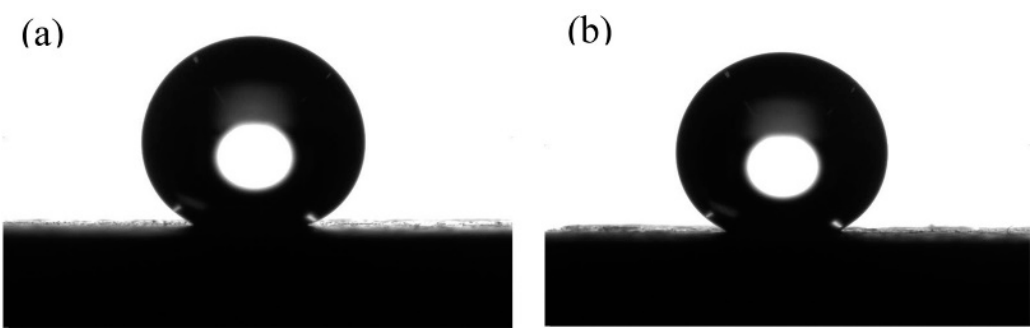

Figure 11. WCA image for stability (a) initial state; (b) after exposure for 6 months.

Besides, the self-cleaning property of super-hydrophobic surfaces also plays an important role in its practical applications. Figure 12 shows the process of the self-cleaning behavior of the as-prepared super-hydrophobic surface in comparison to the control surface. The samples were placed in a glass petri dish at a slope angle of about $10^{\circ}$ and subjected to continuously falling droplets. Graphite powders $(\sim 40 \mu \mathrm{m})$ as contaminants were spread over the sample surfaces. As can be seen from Figure 12(b1-b5) the as-prepared super-hydrophobic galvanized steel plate showed excellent self-cleaning action by allowing the water droplet carry the contamination away from its rolling and bouncing process. However, this is not the case for the control sample as shown in Figure 12(a1-a5), where the contaminants remains. The results indicate that the as-fabricated super-hydrophobic galvanized steel surface has a low-adhesion to the contaminants and can be easily taken away by the rolling-off water droplets. The super-hydrophobic surface exhibits excellent self-cleaning property, which can protect the steel surface free from adhering by pollutants in practical application.

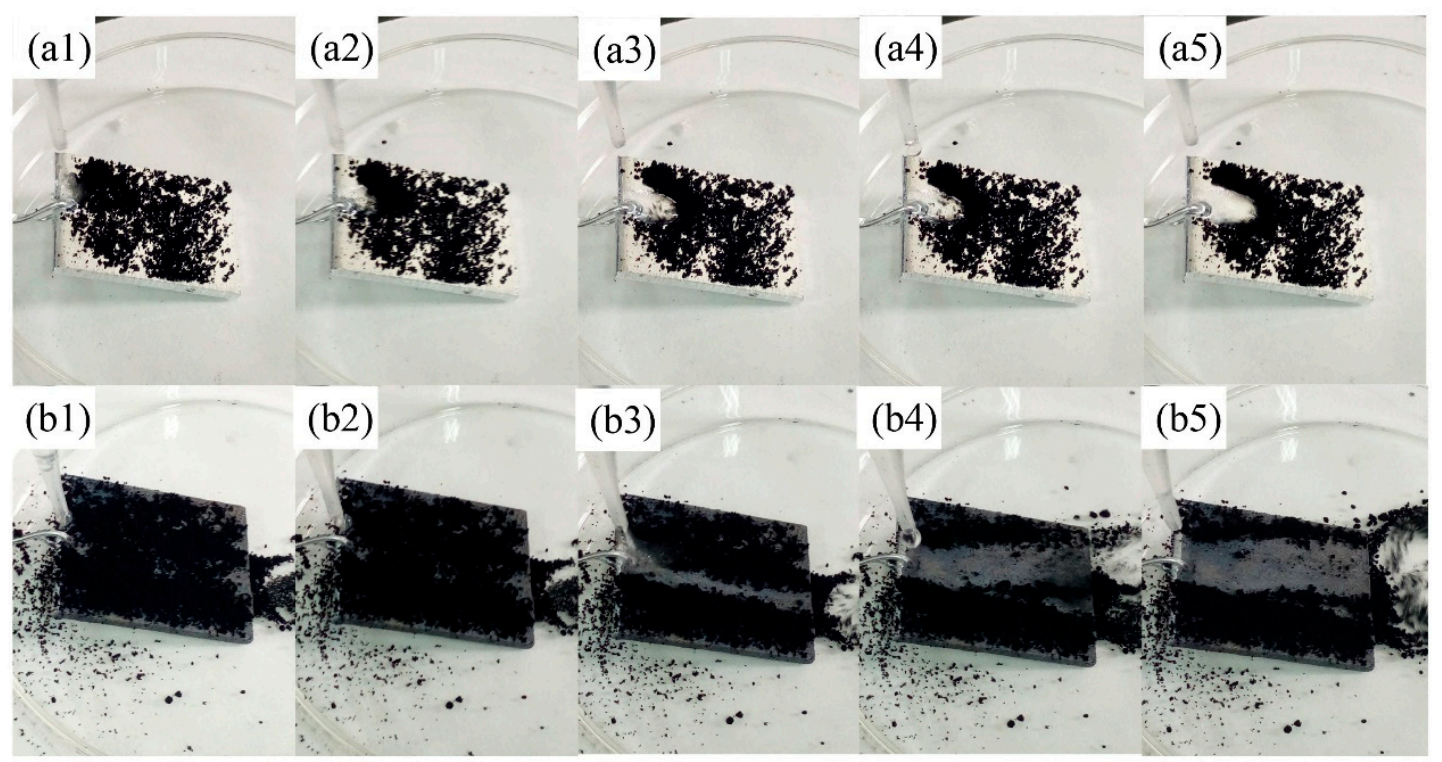

Figure 12. Photographs of the self-cleaning behavior process: (a) the control surface; (b) the super-hydrophobic surface.

\section{Conclusions}

In summary, super-hydrophobic galvanized steel surfaces were successfully fabricated by a facile galvanic replacement reaction and STA modification. The super-hydrophobic surface can be obtained within $3 \mathrm{~min}$. The as-fabricated super-hydrophobic surface is mainly composed of Zinc stearate covered copper agglomerate particles with hierarchical micro/nano structures and has a maximum WCA of $164.3^{\circ}$. The as-prepared super-hydrophobic surface show excellent performance of corrosion resistance in $3.5 \mathrm{wt} \% \mathrm{NaCl}$ aqueous solution by not allowing a large volume of corrosive liquids to interact with the galvanized surface. The formation of air layer on the super-hydrophobic surface that 
acts as a corrosion barrier to inhibit the electron and ion transfer between substrate and electrolyte. The highest inhibition efficiency was estimated to be $96.6 \%$. Furthermore, the as-fabricated film show good chemical stability and long-term durability in air and also exhibit excellent self-cleaning property. This method may provide a fast, green, and cost-effective way to realize the long-term corrosion control for galvanized steel.

Author Contributions: Data curation, C.L.; Investigation, R.M. and A.D.; Methodology, Y.F. and X.Z.; Project administration, X.C.; Writing—original draft, C.L.; Writing—review \& editing, C.L.

Funding: This research was funded by National Natural Science Foundation of China (grant number 51501055, 51601056) and Natural Science Foundation of Hebei Province of China (grant number is E2017202012).

Conflicts of Interest: The authors declare no conflict of interest.

\section{References}

1. Marder, A.R. The metallurgy of zinc-coated steel. Prog. Mater. Sci. 2000, 45, 191-271. [CrossRef]

2. Liu, Y.W.; Wang, Z.Y.; Cao, G.W.; Cao, Y.; Huo, Y. Study on corrosion behavior of zinc exposed in coastal-industrial atmospheric environment. Mater. Chem. Phys. 2017, 198, 243-249. [CrossRef]

3. Kartsonakis, I.A.; Stanciu, S.G.; Matei, A.A.; Hristu, R.; Karantonis, A.; Charitidis, C.A. A comparative study of corrosion inhibitors on hot-dip galvanized steel. Corros. Sci. 2016, 112, 289-307. [CrossRef]

4. Aneja, K.S.; Bohm, S.; Khanna, A.S.; Bohm, H.L.M. Graphene based anticorrosive coatings for Cr(VI) replacement. Nanoscale 2015, 7, 17879-17888. [CrossRef] [PubMed]

5. Wang, D.; Bierwagen, G.P. Sol-gel coatings on metals for corrosion protection. Prog. Org. Coat. 2009, 64, 327-338. [CrossRef]

6. Su, H.Y.; Chen, P.L.; Lin, C.S. Sol-gel coatings doped with organosilane and cerium to improve the properties of hot-dip galvanized steel. Corros. Sci. 2016, 102, 63-71. [CrossRef]

7. Figueira, R.B.; Silva, C.J.R.; Pereira, E.V. Hybrid sol-gel coatings for corrosion protection of hot-dip galvanized steel in alkaline medium. Surf. Coat. Technol. 2015, 265, 191-204. [CrossRef]

8. Eduok, U.; Faye, O.; Szpunar, J. Recent developments and applications of protective silicone coatings: A review of PDMS functional materials. Prog. Org. Coat. 2017, 111, 124-163. [CrossRef]

9. Eduok, U.; Szpunar, J. Bioinspired and hydrophobic alkyl-silanized protective polymer coating for Mg alloy. Prog. Nat. Sci. Mater. Int. 2018, 28, 354-362. [CrossRef]

10. Eduok, U.; Szpunar, J.; Faye, O. Effect of benzothiazole biocide on SRB-induced biocorrosion of hot-dip galvanized steel. Eng. Fail. Anal. 2018, 93, 111-121. [CrossRef]

11. Xia, F.; Jiang, L. Bio-Inspired, Smart, Multiscale Interfacial Materials. Adv. Mater. 2010, 20, 2842-2858. [CrossRef]

12. Ahmad, Z.; Patel, F. Development of Novel Corrosion Techniques for a Green Environment. Int. J. Corros. 2011, 2012, 1-8. [CrossRef]

13. Ahmad, Z.; Khan, A.U.; Farooq, R.; Saif, T. Hydrophobicity-A Green Technique for Enhancing Corrosion Resistance of Alloys. In New Trends in Alloy Development, Characterization and Application; InTechOpen: Rijeka, Croatia, 2015. [CrossRef]

14. Wang, P.; Zhang, D.; Qiu, R.; Wu, J.; Wan, Y. Super-hydrophobic film prepared on zinc and its effect on corrosion in simulated marine atmosphere. Corros. Sci. 2013, 69, 23-30. [CrossRef]

15. Kim, J.-H.; Mirzaei, A.; Woo Kim, H.; Sub Kim, S. Facile fabrication of superhydrophobic surfaces from austenitic stainless steel (AISI 304) by chemical etching. Appl. Surf. Sci. 2018, 439, 598-604. [CrossRef]

16. Li, Y.; Liu, F.; Sun, J. A facile layer-by-layer deposition process for the fabrication of highly transparent superhydrophobic coatings. Chem. Commun. 2009, 19, 2730-2732. [CrossRef] [PubMed]

17. Lu, S.; Chen, Y.; Xu, W.; Liu, W. Controlled growth of superhydrophobic films by sol-gel method on aluminum substrate. Appl. Surf. Sci. 2010, 256, 6072-6075. [CrossRef]

18. Sun, J.; Zhang, F.; Song, J.; Wang, L.; Qu, Q.S.; Lu, Y.; Parkin, I. Electrochemical fabrication of superhydrophobic Zn surfaces. Appl. Surf. Sci. 2014, 315, 346-352. [CrossRef]

19. Zheng, S.; Li, C.; Fu, Q.; Hu, W.; Xiang, T.F.; Wang, Q.; Du, M.P.; Liu, X.C.; Chen, Z. Development of stable superhydrophobic coatings on aluminum surface for corrosion-resistant, self-cleaning, and anti-icing applications. Mater. Des. 2016, 93, 261-270. [CrossRef] 
20. Young, T.J.; Jackson, J.; Roy, S.; Ceylan, H.; Sundararajan, S. Tribological behavior and wettability of spray-coated superhydrophobic coatings on aluminum. Wear 2017, 376-377, 1713-1719. [CrossRef]

21. Xu, W.; Liu, H.; Lu, S.; Xi, J.M.; Wang, Y.B. Fabrication of Superhydrophobic Surfaces with Hierarchical Structure through a Solution-Immersion Process on Copper and Galvanized Iron Substrates. Langmuir 2008, 24, 10895-10900. [CrossRef] [PubMed]

22. Pan, H.; Luo, F.; Lin, G.; Wang, C.W.; Dong, M.M.; Liao, Y.; Zhao, Q.Z. Quasi-superhydrophobic porous silicon surface fabricated by ultrashort pulsed-laser ablation and chemical etching. Chem. Phys. Lett. 2015, 637, 159-163. [CrossRef]

23. Wu, Y.; Zhou, S.; Wu, L. Fabrication of Robust Hydrophobic and Super-Hydrophobic Polymer Films with Onefold or Dual Inverse Opal Structures. Macromol. Mater. Eng. 2016, 301, 1430-1436. [CrossRef]

24. Yan, H.; Wang, Y.; An, Z.; Zhang, J.J.; Yang, H.X. The super-hydrophobic IR-reflectivity $\mathrm{TiO}_{2}$ coated hollow glass microspheres synthesized by soft-chemistry method. J. Phys. Chem. Solids 2016, 98, 43-49.

25. Gao, R.; Wang, J.; Zhang, X.; Yan, H.J.; Yang, W.L.; Liu, Q.; Zhang, M.L.; Liu, L.H.; Takahashi, K. Fabrication of superhydrophobic magnesium alloy through the oxidation of hydrogen peroxide. Colloid Surf. A 2013, 436, 906-911. [CrossRef]

26. Qing, Y.Q.; Yang, C.N.; Zhao, Q.Q.; Hu, C.B.; Liu, C.S. Simple fabrication of superhydrophobic/superoleophobic surfaces on copper substrate by two-step method. J. Alloy Compd. 2016, 695, 1878-1883. [CrossRef]

27. Chen, C.; Yang, S.Y.; Liu, L.Y.; Xie, H.; Liu, H.; Zhu, L.X.; Xu, X.L. A green one-step fabrication of superhydrophobic metallic surfaces of aluminum and zinc. J. Alloy Compd. 2017, 711, 506-513. [CrossRef]

28. Liu, B.J.; Wang, L.L.; Gao, Y.J.; Tian, T.Z.; Min, J.; Yao, J.L.; Xiang, Z.L. Synthesis and characterization of photoreactive silica nanoparticles for super-hydrophobic cotton fabrics application. Text. Res. J. 2015, 85, 795-803. [CrossRef]

29. Zhong, Y.X.; Hu, J.; Zhang, Y.F.; Tang, S.W. The one-step electroposition of superhydrophobic surface on AZ31 magnesium alloy and its time-dependence corrosion resistance in $\mathrm{NaCl}$ solution. Appl. Surf. Sci. 2017, 427, 1193-1201. [CrossRef]

30. Lu, Z.; Wang, P.; Zhang, D. Super-hydrophobic film fabricated on aluminium surface as a barrier to atmospheric corrosion in a marine environment. Corros. Sci. 2015, 91, 287-296. [CrossRef]

31. Wang, P.; Zhang, D.; Qiu, R.; Hou, B.R. Super-hydrophobic film prepared on zinc as corrosion barrier. Corros. Sci. 2011, 53, 2080-2086. [CrossRef]

32. Qu, M.; Zhang, B.; Song, S.; Chen, L.; Zhang, J.; Cao, X. Fabrication of Superhydrophobic Surfaces on Engineering Materials by a Solution-Immersion Process. Adv. Funct. Mater. 2010, 17, 593-596. [CrossRef]

33. Guo, Z.; Zhou, F.; Hao, J.; Liu, W. Effects of system parameters on making aluminum alloy lotus. J. Colloid Interface Sci. 2006, 303, 298-305. [CrossRef] [PubMed]

34. Wu, R.; Liang, S.; Pan, A.; Yuan, Z.; Tang, Y.; Tan, X.; Guan, D.; Yu, Y. Fabrication of nano-structured super-hydrophobic film on aluminum by controllableimmersing method. Appl. Surf. Sci. 2012, 258, 5933-5937. [CrossRef]

35. Qian, B.; Shen, Z. Fabrication of superhydrophobic surfaces by dislocation-selective chemical etching on aluminum, copper, and zinc substrates. Langmuir ACS J. Surf. Colloids 2005, 21, 9007-9009. [CrossRef] [PubMed]

36. Song, J.; Xu, W.; Liu, X.; Lu, Y.; Wei, Z.F.; Wu, L.B. Ultrafast fabrication of rough structures required by superhydrophobic surfaces on Al substrates using an immersion method. Chem. Eng. J. 2012, 211-212, 143-152. [CrossRef]

37. Cao, L.; Liu, J.; Huang, W.; Li, Z.L. Facile fabrication of superhydrophobic surfaces on zinc substrates by displacement deposition of Sn. Appl. Surf. Sci. 2013, 265, 597-602. [CrossRef]

38. Tao, N.; Xu, W.; Lu, S. Fabrication of superhydrophobic surfaces on zinc substrates. Appl. Surf. Sci. 2011, 258, 1359-1365.

39. Qi, Y.; Cui, Z.; Liang, B.; Parnas, R.S.; Lu, H.F. A fast method to fabricate superhydrophobic surfaces on zinc substrate with ion assisted chemical etching. Appl. Surf. Sci. 2014, 305, 716-724. [CrossRef]

40. Sarkar, D.K.; Saleema, N. One-step fabrication process of superhydrophobic green coatings. Surf. Coat. Technol. 2010, 204, 2483-2486. [CrossRef]

41. Phankosol, S.; Sudaprasert, K.; Lilitchan, S.; Aryusuk, K.; Krisnangkura, K. Estimation of surface tension of fatty acid methyl ester and biodiesel at different temperatures. Fuel 2014, 126, 162-168. [CrossRef] 
42. Cheng, Y.Y.; Lu, S.X.; Xu, W.G.; Boukherroub, R.; Szunerits, S.; Liang, W. Controlled fabrication of NiO/ZnO superhydrophobic surface on zinc substrate with corrosion and abrasion resistance. J. Alloy Compd. 2017, 723, 225-236. [CrossRef]

43. Huang, Y.; Sarkar, D.K.; Chen, X.G. Fabrication of Corrosion Resistance Micro-Nanostructured Superhydrophobic Anodized Aluminum in a One-Step Electrodeposition Process. Metals 2016, 6, 47. [CrossRef]

44. Wertheim, G.K.; Campagna, M.; Hüfner, S. Density of states of Zn and $\beta$-Brass. Phys. Condens. Matter 1974, 18, 133-139. [CrossRef]

45. Shirtcliffe, N.J.; Mchale, G.; And, M.I.N.; Perry, C.C. Wetting and wetting transitions on copper-based super-hydrophobic surfaces. Langmuir 2005, 21, 937-943. [CrossRef] [PubMed]

46. Martines, E.; Seunarine, K.; Morgan, H.; Gadegaard, N.; Wilkinson, C.D.W.; Riehle, M.O. Superhydrophobicity and superhydrophilicity of regular nanopatterns. Nano Lett. 2005, 5, 2097-2103. [CrossRef] [PubMed]

47. Singh, B.P.; Nayak, S.; Nanda, K.K.; Jena, B.K.; Bhattacharjee, S.; Besra, L. The production of a corrosion resistant graphene reinforced composite coating on copper by electrophoretic deposition. Carbon 2013, 6 , 147-156. [CrossRef]

(c) 2018 by the authors. Licensee MDPI, Basel, Switzerland. This article is an open access article distributed under the terms and conditions of the Creative Commons Attribution (CC BY) license (http:/ / creativecommons.org/licenses/by/4.0/). 